\title{
Implementação de governança familiar em uma empresa de transportes do interior de São Paulo
}

\author{
Implementation of family governance in a transportion company in São Paulo
}

\author{
Gustavo Bagni ${ }^{1 *}{ }^{\circ}$; Cassia Renata Pinheiro² ${ }^{\infty}$
}

Received: jul. 25, 2019

Accepted: mai. 25, 2020

${ }^{1}$ Engenheiro de Produção. Rua 5, no 3399 - Jardim Portugal; 13504-114; Rio Claro, São Paulo, Brasil

2 PECEGE. Professor associado. Rua Alexandre Herculano 120, sala T4 - Bairro Vila Monteiro; 13418-445; Piracicaba, SP, Brasil *autor correspondente: gustavobagni@uol.com.br
Este é um artigo publicado em acesso aberto (Open Access) sob a licença Creative Commons Attribution, que permite uso, distribuição e reprodução em qualquer meio, sem restrições desde que o trabalho original seja corretamente citado.
Resumo: As empresas familiares apresentam índices significativos de mortalidade, sendo o processo de sucessão do fundador crucial para sua sobrevivência. Ao contrário de empresas de capital aberto, a sucessão na empresa familiar envolve alterações nas dimensões família, propriedade e empresa. A utilização de mecanismos de governança nesse processo é útil para auxiliar na separação de papéis de cada indivíduo e para formalização de fóruns de debate para cada uma das dimensões. Contudo, devido a limitação de recursos, muitas vezes é necessário priorizar a implementação de alguns mecanismos. Dado esse contexto, o objetivo deste trabalho foi entender qual a importância de cada mecanismo de governança familiar no processo de sucessão. Para tanto, foi realizado um estudo de caso em uma empresa de transportes que implementou três dos quatro principais mecanismos de governança familiar citados na literatura. Por meio de entrevistas, consultas a documentos e observação de uma reunião do conselho de administração foi avaliada a percepção de importância dos sócios, familiares e funcionários em relação a cada mecanismo de governança familiar. A diretoria executiva e o conselho de administração foram identificados como os mecanismos mais importantes, enquanto o conselho de sócios e o conselho familiar tornam-se relevantes em determinadas situações e para grupos específicos. Desse modo, recomenda-se priorizar a implementação da diretoria executiva e do conselho de administração em relação aos demais mecanismos de governança familiar.

Palavras-chave: empresa familiar; governança coorporativa; sucessão familiar.

\begin{abstract}
Family business has significant mortality rates, with the founder's succession process crucial for their survival. Unlike public companies, succession in family business involves changes in the family, property and business dimensions. The use of governance mechanisms in this process is useful to help in separating the roles of each individual and formalizing discussion forums for each dimension. However, due to limited resources, it is often necessary to prioritize the implementation of some mechanisms. Given this context, the objective of this work was to understand the importance of each family governance mechanism in the succession process. A case study was carried out in a transport company that implemented three of the four main mechanisms of family governance cited in the literature. Through interviews, consultation of documents and observation of a meeting of the board of directors, it was evaluated the perception of importance of partners, family and employees about each family governance mechanism. Top management and board of directors have been identified as the most important mechanisms, while shareholders meeting and family council become relevant in specific situations and groups. Therefore, it is recommended to prioritize the implementation of top management and board of directors in relation to other mechanisms of family governance.
\end{abstract}

Keywords: family business; corporate governance; family succession. 


\section{Introdução}

Utilizando como definição de empresa familiar aquela em que o controle acionário está concentrado em uma única família, tem-se que aproximadamente $70 \%$ do PIB mundial é gerado por empresas familiares (Tharawat Magazine, 2014). Em economias emergentes, em geral, a participação é superior à média mundial, como no Brasil (85\%) e no México (90\%). As empresas familiares não se restringem apenas a pequenas empresas, incluindo grandes organizações, como Itaú-Unibanco, Votorantim, Natura, Editora Abril, Grupo Silvio Santos, entre outras (Garcia e Tavares, 2017; Gersick et al., 2017).

Em contraste com sua relevância econômica, as empresas familiares apresentam índices significativos de mortalidade. Apenas $30 \%$ das empresas familiares atingem a segunda geração, e somente $5 \%$ a terceira (Prado, 2011). Essa realidade é, à primeira vista, contraditória, pois nas empresas familiares existe maior preocupação com a perpetuação futura do negócio (Transgenerational Orientation (TGO)), maior horizonte de tempo para investimentos, maiores níveis de motivação e retenção de funcionários e maior preocupação com a imagem da empresa e sua associação com a reputação da família (Muttakin et al., 2015; Nekhili et al., 2017; Stein, 1988; Steinberg e Blumenthal, 2011; Tagiuri e Davis, 1996; Zellweger et al., 2012;).

O processo de sucessão em empresas familiares, contudo, é ponto crucial na continuidade das empresas familiares, especialmente quando o fundador adoece ou falece (Brenes et al., 2011; Gersick et al., 2017; Lefebvre e Lefebvre, 2016; Mathews e Blumentritt, 2015; Steinberg e Blumenthal, 2011). Inicialmente, a influência dos fundadores é muito grande nas empresas familiares, uma vez que eles atuam desde o controle dos processos produtivos e financeiros até a definição de estratégias (Nascimento et al., 2016). É usual, também, que grande parte das decisões sejam centralizadas, bem como que o fundador seja o chefe das três dimensões, exercendo o papel de chefe da família, CEO e presidente do conselho (Gersick et al., 2017).

Ao contrário de empresas de capital aberto, em que a sucessão envolve apenas troca do CEO, em empresas familiares, a sucessão pode implicar em alterações nas dimensões da família, na gestão da empresa e na divisão do controle da propriedade. Alterações na dimensão propriedade, especialmente, tornam a sucessão muito complexa. Um exemplo é a transição entre o estágio do Proprietário Controlador (propriedade controlada por uma única pessoa) para o estágio da Sociedade entre Irmãos (propriedade dividida entre alguns parentes).

Nesse contexto, a utilização de mecanismos de governança é útil, pois permite separar os fóruns de debates das diferentes dimensões que compõem uma empresa familiar, além de auxiliar na continuidade da empresa, especialmente em estágios em que há a divisão da propriedade entre diferentes pessoas (Garcia e Tavares, 2017; Oliveira et al., 2012; Steinberg e Blumenthal, 2011). A governança possibilita também a separação dos diferentes papéis que os membros de uma empresa familiar possuem através de suas estruturas de gestão, já que, enquanto um irmão pode estar presente nas três dimensões, outro pode estar presente apenas na dimensão da família e da propriedade. Por essas razões, a governança é o tópico mais estudado em negócios familiares (Yu et al., 2012).

Contudo, dada a limitação de recursos financeiros e intelectuais, é essencial que os mecanismos de governança familiar mais importantes recebam maior atenção nos estágios iniciais, como aborda a teoria dos Fatores Críticos do Sucesso (Howell, 2009; Rockart, 1979). Nesse contexto, o objetivo deste trabalho é entender, por meio de um estudo de caso, qual a importância de cada mecanismo de governança familiar em uma empresa em sua continuidade após ter realizado a transição do estágio do Proprietário Controlador para a Sociedade entre Irmãos. Especificamente, busca-se avaliar quais mecanismos foram implementados, como funcionam e quais benefícios trouxeram para a empresa, na visão dos proprietários, familiares e funcionários.

\section{Material e Métodos}

Foi realizado um estudo de caso único retrospectivo em uma empresa de transportes do interior do estado de São Paulo. Um dos autores já conhecia previamente a empresa e sua evolução, o que viabilizou a realização de pesquisa bem como a definição das fases de coleta de dados, como posteriormente será explicado. 
A empresa estudada passou recentemente por um processo de sucessão não planejado, recorrendo a mecanismo de governança familiar para estabelecer o relacionamento entre os familiares e membros da empresa nas diferentes dimensões em que atua.

Foram utilizados os seguintes critérios para seleção desse caso:

- O fundador faleceu recentemente, iniciando um processo de transição para seus filhos;

- A sucessão inicialmente planejada era para um único filho, o que não ocorreu, pois ele também faleceu, iniciando-se, assim, uma sociedade entre irmãos não planejada;

- O pesquisador obteve livre acesso da empresa para analisar o processo de implementação da governança familiar;

- Os sócios concordaram em conceder entrevistas ao pesquisador sobre o tema deste artigo.

Para analisar a importância dos mecanismos de governança corporativa foi necessário construir um panorama do desenvolvimento da empresa foco, uma vez que sua construção é fundamental para compreender as decisões tomadas pela organização em seus mecanismos de governança coorporativa, bem como o relacionamento entre seus membros. Assim, foram consultados documentos do processo de sucessão para entender o funcionamento dos mecanismos de governança implementados, bem como as regras existentes para seu funcionamento.

Inicialmente, foi construído um breve histórico descritivo da empresa e identificou-se três fases principais de sua evolução: fundação, expansão (fundador e filho trabalhando juntos) e maturidade (após a morte do fundador e do filho). Essas três fases foram definidas após a análise dos dados, seguindo o modelo tridimensional do desenvolvimento da empresa familiar. 0 papel de cada membro da família em cada uma das três fases foi também classificado, utilizando-se o modelo dos três círculos, fundamental para entender as motivações de cada pessoa, bem como seu posicionamento em cada um dos mecanismos de governança coorporativa.

Compreendida a evolução da empresa, foram levantados na literatura, quais os mecanismos de governança familiar mais importantes e usuais, suas características e regras gerais de funcionamento. Então, os mecanismos implementados na empresa foco foram comparados com a literatura, buscando-se identificar se a prática na empresa era similar à teoria.

Para entender a importância de cada mecanismo, foram realizadas entrevistas com sócios, funcionários e familiares, nas quais eles foram questionados, após uma breve explicação sobre o que era cada mecanismo, quais eles consideravam os mais importantes para a continuidade da empresa após o processo de sucessão. As respostas subjetivas recebidas foram classificadas pelos pesquisadores em:

- Alta importância: quando a maioria dos respondentes afirmou que consideravam o mecanismo importante;

- Média importância: quando houve divergência de opiniões, com número significativo de respondentes afirmando que o mecanismo era importante e outro grupo representativo afirmando que não era;

- Baixa importância: quando a maioria dos respondentes afirmou que não considerava o mecanismo importante.

Para aumentar a validade da pesquisa é importante realizar a triangulação de informações, a qual consiste em obter informações de múltiplas fontes (Voss et al., 2002). Para o presente estudo de caso, foram utilizados quatro meios de coletas de dados: i) consulta a documentos; ii) entrevistas semiestruturadas com quatro dos seis sócios; iii) entrevistas não estruturadas com quatro funcionários e cinco familiares e; iv) observação de uma reunião do conselho de administração.

As entrevistas foram realizadas em salas fechadas, com a presença apenas do pesquisador e do entrevistado. 0 pesquisador anotou, ao longo da entrevista, as principais observações e comentários do entrevistado. Ao final da entrevista, o pesquisador leu em voz alta suas anotações para que o entrevistado 
confirmasse se elas correspondiam ao que ele havia dito. Caso o entrevistado verificasse alguma inconsistência, a anotação era revisada pelo pesquisador na presença do entrevistado.

Nas entrevistas semiestruturadas, algumas das perguntas utilizadas foram:

- Antes do fundador adoecer, como você imaginava que a empresa funcionaria após a sucessão?

- Como a empresa sobreviveu à morte em curto espaço de tempo do sucessor e de seu filho mais velho?

- Você deseja continuar sendo sócio na empresa ou tem interesse em vendê-la? Justifique sua decisão?

- Como é o relacionamento atual entre os sócios?

- A implantação da reunião do conselho de administração alterou esses relacionamentos? De que forma?

- Como você compartilha as informações do conselho de administração com seu núcleo familiar (filhos, netos, cônjuge, entre outros)?

- Como é o relacionamento dos sócios com os administradores?

- Na sua opinião, existem mecanismos e regras claros para medir a performance e regular a atuação dos administradores?

Por fim, observou-se uma reunião do conselho de administração, para que os pesquisadores verificassem a coerência das dinâmicas familiares que haviam identificado, bem como o funcionamento do próprio conselho de administração, dado que esse mecanismo mostrou-se um dos mais importantes ao longo da pesquisa.

\section{Resultados e Discussão}

A empresa foco desta pesquisa foi fundada em 1967 por um casal que havia interrompido os estudos na quarta série do Ensino Fundamental. 0 fundador, que trabalhava como motorista de ônibus, recebeu um caminhão como herança de seu pai, assim como seus irmãos. Uma vez que um de seus irmãos não quis ficar com seu caminhão, o fundador adquiriu uma dívida para ser capaz de comprá-lo e contratar um funcionário para dirigi-lo, já que ele dirigia o próprio caminhão. A fundadora, por sua vez, ficava na base da empresa, recebendo ligações e realizando a manutenção dos caminhões. Assim, em janeiro de 1967, a empresa foi fundada - inicialmente, transportando leite e derivados para uma marca muito importante no estado de São Paulo.

Posteriormente, com uma frota de treze caminhões, o fundador recebeu, de seu cunhado, uma proposta para trabalhar com o transporte de petróleo e seus derivados. Enquanto o cunhado negociava os fretes (comercial), o fundador fornecia os caminhões e motoristas. Contudo, após alguns anos, o fundador desfez o modelo, por considerar que o valor recebido não era proporcional a quantidade de trabalho que realizava. Então, ele passou por grandes dificuldades, pois ficou por algum tempo sem demanda de trabalho, o que quase causou a falência da empresa. Contudo, após algum tempo e com muita dificuldade, ele mesmo passou a negociar os fretes com os clientes, estratégia adotada desde então.

A empresa continuou expandindo-se e o filho mais velho do fundador entrou para a empresa, inicialmente tomando conta de apenas uma das sedes. Contudo, duas décadas mais tardes, fundador e filho passaram a gerir a empresa em conjunto, momento em que a fundadora não participava mais ativamente da empresa. Mais dez anos se passaram e o fundador começou a apresentar problemas de saúde, limitando sua participação na empresa. Assim, a empresa preparou-se para uma sucessão direta (quanto a gestão da empresa, não quanto a propriedade) do pai para o filho mais velho. Contudo, inesperadamente, o filho mais velho adoeceu, logo após o falecimento do pai, falecendo 9 após meses. Assim, os outros filhos e os netos, até então pouco influentes no cotidiano da empresa, passaram a administrá-la. A pesquisa foi realizada cerca de dois anos após essa transição, momento em que os mecanismos de governança familiar já estavam implementados (com o auxílio de uma consultoria externa especializada em sucessão familiar e governança, contratada pela empresa). 


\section{Definição de Empresa Familiar}

A principal característica que diferencia as empresas familiares das não-familiares é a interação entre família e empresa, com o mesmo grupo de pessoas integrando as duas dimensões (Dyer Jr. e Dyer, 2009). Esse é o caso da empresa foco, em que o fundador era tanto chefe da família como presidente da empresa. Posteriormente, seu filho passou a desempenhar papel semelhante, especialmente após o pai adoecer.

As dimensões, contudo, apresentam características muito diferentes entre si e sua inter-relação gera grande complexidade (Gersick et al., 2017). Enquanto o foco da família está em questões sociais e na integridade de seus membros, a empresa foca em questões econômicas e competitivas. (Steinberg e Blumenthal, 2011; Tagiuri e Davis, 1996)

Segundo Harms (2014), Donnelley (1964) foi o pioneiro na literatura a definir o que é uma empresa familiar, caracterizando-a pela ligação mútua entre a política da companhia e os objetivos e interesses da família, além da presença concomitante de ao menos duas gerações da família. A empresa foco enquadra-se nesse conceito, porém não em seu estágio inicial, mas a partir do momento em que o filho do fundador assume a liderança da organização. Até hoje, contudo, não existe um conceito consolidado de empresa familiar na literatura (Dawson e Mussolino, 2014; Garcia e Tavares, 2017; Gedajlovic et al., 2012; Harms, 2014; Steiger et al., 2015).

As diferentes definições apresentadas, usualmente, abrangem o envolvimento de uma família em uma ou mais das três seguintes esferas, a saber: i) controle acionário (Gallo e Sveen, 1991; Gonçalvez, 2000; Litz, 1995; Pimenta e Abreu, 2014; Tondo, 2008); ii) envolvimento na gestão dos negócios (Gallo e Sveen, 1991; Gonçalvez, 2000; Litz, 1995; Longenecker et al., 1997; Tondo, 2008) e; iii) transição multigeracional (Lodi, 1998; Werner, 2011).

A organização foco apresenta envolvimento em pelo menos duas dessas esferas: controle acionário e envolvimento dos negócios. A transição multigeracional está presente, em parte, pelo objetivo da transição planejada de pai para filho. Contudo, essa transição não foi estruturada, mas resultado natural do envolvimento do filho nos negócios e do desenvolvimento de suas habilidades de liderança, permitindo que ele ocupasse uma posição próxima ao pai nas decisões da empresa.

\section{Modelo dos Três Círculos}

Para entender a dinâmica das empresas familiares, bem como seus conflitos e motivações, Taguri e Davis (1996) desenvolveram o Modelo Três Círculos, o qual se popularizou por sua simplicidade (Gersick et al., 2017). Inicialmente, o modelo foi publicado considerando apenas dois subsistemas, na tese de Davis, em 1982. Posteriormente, no entanto, ocorreu a divisão entre os subsistemas propriedade e gerenciamento (Garcia e Tavares, 2017).

No modelo, cada subsistema é representado por um círculo, cada qual com uma lógica diferente, segundo Steinberg e Blumenthal (2011):

- Família: ênfase no afeto, incluindo sentimentos positivos (como amor) e negativos (como ciúme e rivalidade);

- Propriedade: ênfase no dinheiro;

- Empresa: ênfase no poder.

A sobreposição dos círculos representa as sete diferentes posições que uma pessoa pode ocupar em uma empresa familiar (Figura 1). Pessoas com apenas uma ligação com a empresa (posições de 1 a 3), posicionam-se nos setores externos dos círculos. Pessoas com duas ou três ligações, estão posicionadas na sobreposição dos círculos (Gersick et al., 2017). 


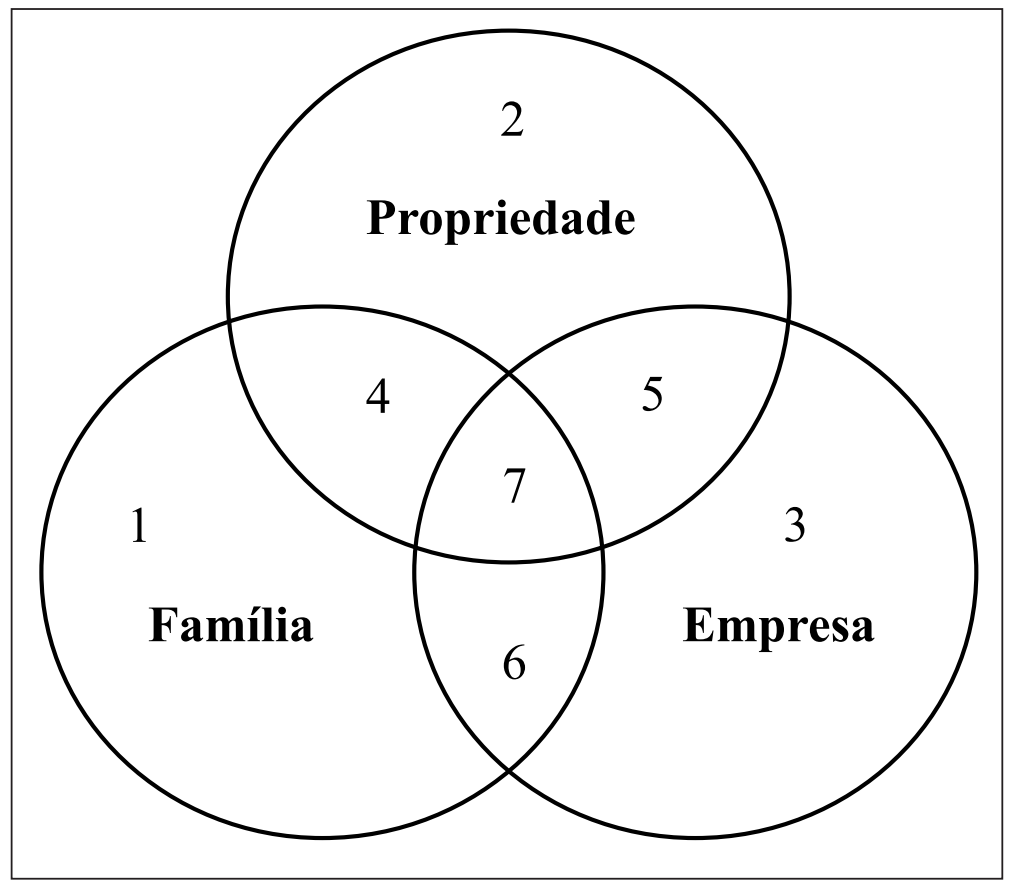

Figura 1. Modelo dos Três Círculos Fonte: Gersick et al. (2017)

Posicionar corretamente cada pessoa envolvida é importante para entender as motivações, conflitos e relações. Steinberg e Blumenthal (2011) citam um exemplo no qual uma pessoa que é apenas proprietária requer aumento de dividendos (ênfase no dinheiro). Outra pessoa, gestora da empresa, é contra, porque quer direcionar os recursos para expandir a empresa (ênfase no poder). Contudo, as pessoas podem ser irmãs, com um relacionamento próximo, criando ainda maiores dificuldades na tomada de decisão.

Em algumas situações, os ciclos não estão bem separados (estrutura diferenciada), como apresentado na Figura 1. Contudo, existem situações, especialmente no início da empresa familiar, em que a identidade e o patrimônio da família são confundidos com os da empresa. Nesse caso, há alta sobreposição entre os três círculos e a estrutura é denominada fusionada.

$\mathrm{Na}$ empresa foco, pode-se destacar três fases evolutivas bem distintas, como será explorado na próxima seção. A primeira fase é a fundação da empresa e sua evolução inicial, momento em que o casal de fundadores trabalhava na empresa e, também, eram os únicos proprietários do negócio (ocupavam a posição 7). Os filhos, por sua vez, eram pequenos e participavam apenas da família (posição 1). Nessa fase, assim como na seguinte, a estrutura é fusionada. Contudo, para facilitar a visualização dos círculos, na Figura 2 eles são apresentados com a mesma distribuição espacial em todas as fases.

A segunda fase é caracterizada pela participação ativa do filho mais velho nos negócios, o qual passa a abrir, juntamente com seu pai, empresas paralelas à principal (posição 7). Como a fundadora deixa de participar da organização, ela passa a ocupar a posição 4. Também é importante destacar que dois netos e um genro do fundador também passaram a trabalhar na empresa, ocupando a posição 6 do modelo. As filhas do fundador, assim como a maioria de seus netos e demais membros da família ocupam a posição 1.

A terceira fase, por sua vez, caracteriza-se pela ausência do fundador e de seu filho (ambos já falecidos). Nesse momento, nota-se a distribuição da propriedade entre a fundadora, suas três filhas e seus dois netos. Note que apenas um dos netos participa da empresa (ocupando a posição 7). Ele anteriormente ocupava a posição 6 , na fase 2 . Também se verifica que três membros da família (um cunhado e dois netos) trabalhavam na empresa, porém, ainda sem participação acionária em seu controle. 


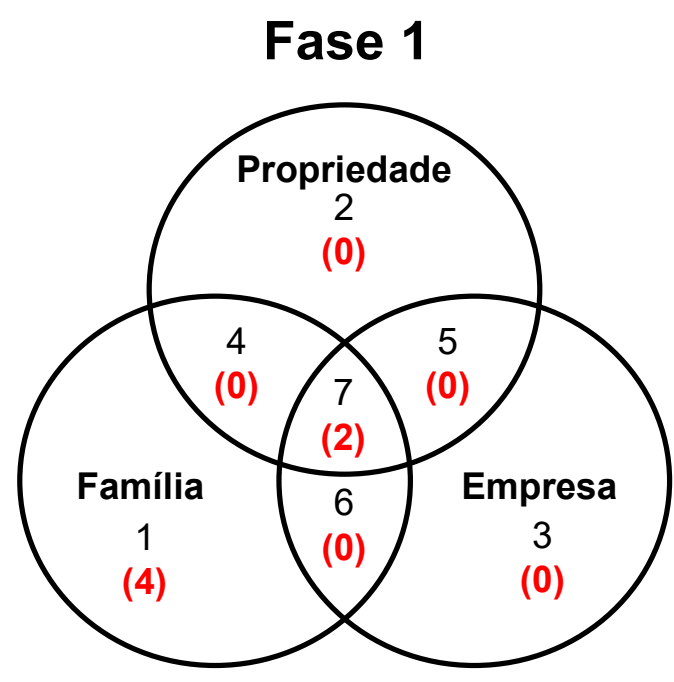

Fase 3
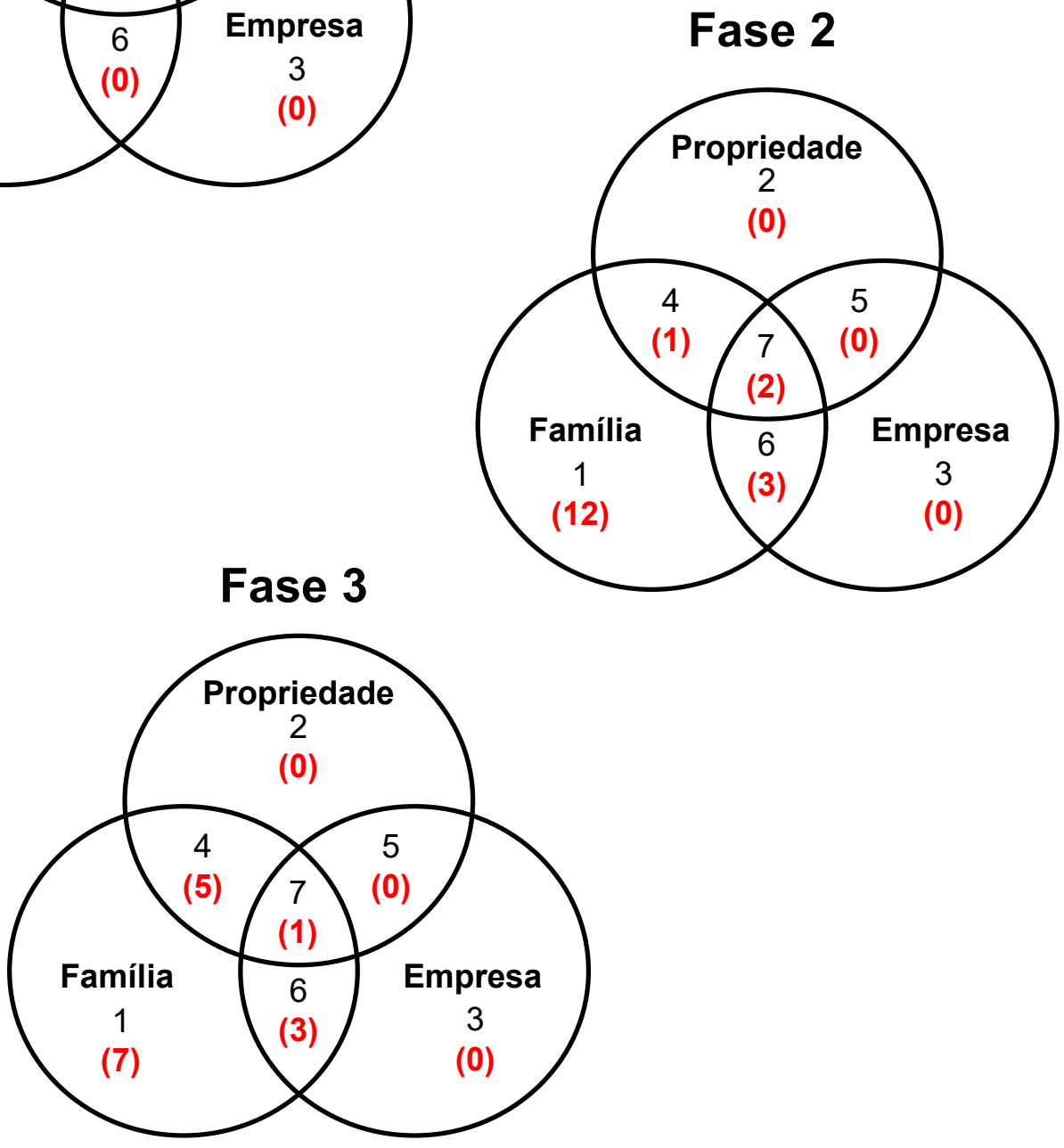

Figura 2. Aplicação do modelo dos três círculos à empresa foco Fonte: Resultados originais da pesquisa

É importante, também, destacar que, como o foco desta pesquisa é na relação entre a família e a empresa, os funcionários que não fazem parte da família não são apresentados na posição três dos diagramas. Além disso, como o controle acionário da organização pertence unicamente aos membros da família, em nenhuma das fases as posições 2 e 5 do modelo foram ocupadas.

\section{Modelo Tridimensional do Desenvolvimento da empresa familiar}

O modelo dos Três Círculos, contudo, é estático. Assim, Gersick et al. (2017) propuseram o Modelo Tridimensional de Desenvolvimento da empresa familiar, que apresenta a evolução dos três subsistemas ao longo do tempo (Figura 3). 


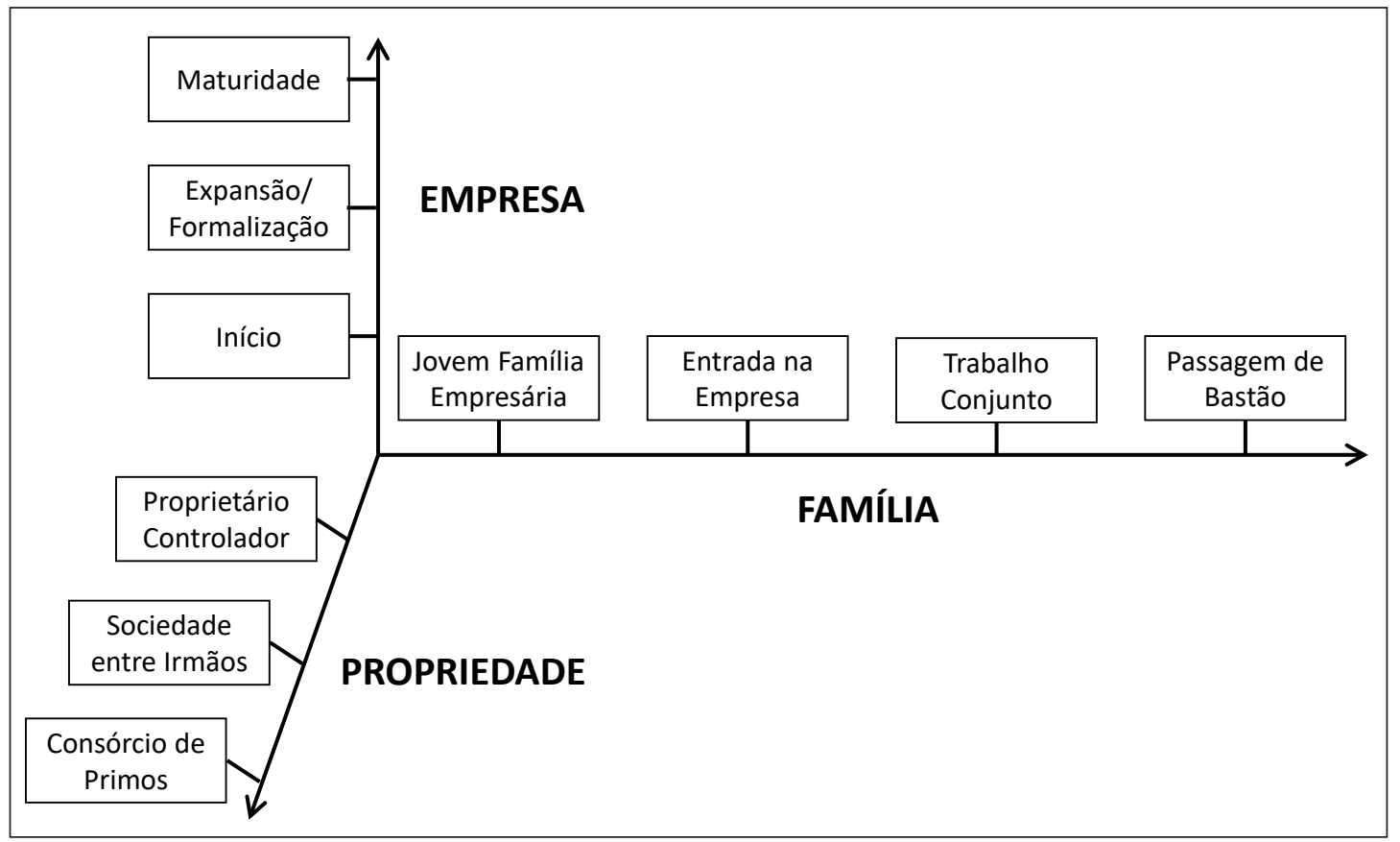

Figura 3. Modelo Tridimensional do Desenvolvimento da empresa familiar Fonte: Gersick et al. (2017)

Na dimensão empresa, o objetivo principal do primeiro estágio é a sobrevivência da organização, com a centralização das decisões no fundador (Garcia e Tavares, 2017). No segundo estágio, o objetivo é expandir e formalizar o negócio, podendo ocorrer delegação de poder e entrada de funcionários não-familiares na empresa (Ramadani e Hoy, 2015). A maturidade, por sua vez, é caracterizada pela estagnação do negócio, buscando-se renovações para evitar a morte da empresa, voltando a um dos estágios anteriores (Gersick et al., 2017).

$\mathrm{Na}$ classificação utilizada para as três fases da organização foco, a empresa encontra-se em diferentes estágios da dimensão organização em cada uma delas. Na fase dois, por exemplo, nota-se a delegação de poder do fundador para seu filho como característica marcante. A literatura destaca que, com o aumento da expectativa de vida, é cada vez mais usual que diferentes gerações trabalhem em conjunto na empresa. Cada um dos núcleos familiares encontra-se em um estágio diferente, composição que Brown (2006) denomina tapeçaria familiar.

Na dimensão família, a literatura propõe quatro estágios evolutivos. 0 estágio inicial caracteriza-se pelo trabalho intenso dos fundadores, pelo equilíbrio entre o trabalho e a família e pela preocupação com a educação dos filhos (Gersick et al., 2017). Em um segundo momento, discute-se as regras de entrada para os sucessores e os filhos começam a deixar a casa dos pais. 0 terceiro estágio é caracterizado pelo trabalho em conjunto dos fundadores e sucessores na gestão da empresa, tendo como características essenciais a comunicação e a cooperação. Por fim, o quarto estágio é a passagem de bastão dos fundadores para os sucessores (Ramadani e Hoy, 2015).

$\mathrm{Na}$ empresa foco, contudo, observou-se duas diferenças significativas em relação à literatura. A primeira é a inexistência do estágio dois, de modo que a empresa evolui do primeiro diretamente para o terceiro estágio, com a entrada apenas do filho mais velho na empresa, o qual passou a ser gestor da organização junto com o pai. A segunda é que não ocorreu a passagem de bastão do fundador para seu(s) sucessor(es), uma vez que a organização já possuía um modelo estabelecido do fundador e de seu filho mais velho. A entrada das filhas no negócio ocorreu sem um processo de transição planejado, impactando na perda significativa do conhecimento existente na organização.

A evolução da dimensão propriedade, dada sua influência no processo de sucessão, será discutida com maiores detalhes (Parada, Müller e Gimeno, 2016). Inicialmente, o controle acionário na empresa é concentrado unicamente no fundador (Proprietário Controlador), que pode obter vantagens pela 
inexistência de brigas pelo poder (Massis et al., 2016). Esse é o caso da Fase 1 da organização estudada, em que a propriedade concentra-se no casal de fundadores.

Ao final de sua vida, o fundador pode querer manter o controle majoritário com uma única pessoa ou dividi-la igualmente entre os filhos (Gersick et al., 2017). Na primeira situação, usual quando há um filho muito mais velho que os outros, mais próximo do pai ou um líder natural de sua geração, permanece o estágio do Proprietário Controlador. No Brasil, esse cenário não é possível pela legislação, mas uma alternativa é a concentração da gestão da empresa em único filho, que dirige a organização no mesmo modelo do fundador, sem respeitar os interesses dos demais acionistas.

Na empresa foco, esse era o caminho que o fundador desejava seguir, estando presentes, em parte, os três aspectos citados por Gersick et al. (2017). O filho era mais velho, porém, com uma diferença de apenas dois anos em relação a primeira filha. Ele era muito próximo ao pai, especialmente por ter entrado cedo na empresa, dado que, desde o início da faculdade, já participava da organização durante as férias. Além disso, por meio de entrevistas com os atuais sócios da organização e parentes do falecido filho do fundador, notou-se claramente que ele, entre os irmãos, possuía habilidades diferenciadas de liderança. Por fim, notou-se um quarto aspecto relevante: o fato de existir um único filho homem, portanto, o único a ter participação direta na empresa, considerando-se a cultura da família, na qual apenas os homens deveriam fazer parte direta do negócio (sendo a participação da fundadora e matriarca da família uma exceção, dadas as condições iniciais da empresa).

Caso o fundador decida pela divisão igualitária entre os filhos, passa-se para a Sociedade entre Irmãos. Pontos críticos desse estágio são a forma como as decisões serão tomadas (sem o fundador), quem irá liderar a tomada de decisão, qual o papel dos sócios que não trabalham na empresa, manutenção da unidade da família e regras para entrada da terceira geração (netos do fundador) (Steinberg e Blumenthal, 2011). É também ponto de conflito o interesse dos sócios não-funcionários de receber maiores dividendos, enquanto os sócios funcionários querem priorizar o reinvestimento de capital para expansão da empresa. Essa estrutura permite sinergia de habilidades e talentos diferentes dos irmãos, mas requer que eles aceitem a interdependência entre eles. Outro ponto favorável da estrutura é que ela aumenta a probabilidade de continuidade da empresa, uma vez que esta não depende mais de uma única pessoa.

Apesar do desejo do fundador de seguir o primeiro caminho, em decorrência do falecimento de seu filho mais velho, a organização acabou seguindo o segundo (Fase 3). Como não foi essa a trajetória planejada, os pontos de conflitos gerados pela divisão de propriedade precisaram ser alinhados após a transição, criando instabilidade para a continuidade da organização. Esse foi o principal motivador da família optar pela contratação de uma consultoria especializada em sucessão familiar e governança.

Por fim, o mais usual é que a Sociedade entre Irmãos evolua para o Consórcio entre Primos (Gersick et al., 2017). Esse estágio caracteriza-se por alta diluição da propriedade e maior distanciamento entre os sócios. Nesse estágio podem conviver membros de várias gerações da família e os interesses com a empresa estão mais ligados a retornos financeiros do que à preservação da memória do fundador e da própria empresa. Ao longo do tempo, a diluição da propriedade pode ser tão grande, que a empresa pode assemelhar-se a uma organização de capital aberto.

\section{Governança Familiar}

A Governança Coorporativa visa aumentar o valor da organização e contribuir para sua continuidade, monitorando o relacionamento entre seus diferentes membros, sejam eles acionistas, conselheiros, diretores, entre outros (IBGC, 2008). Ela consiste em mecanismos voluntários estabelecidos pelos indivíduos, que facilitam e fortalecem as relações entre os membros da família, visando a melhor tomada de decisão na direção da visão da família e assegurando o controle (Suáre e Santana-Martín, 2004; Suess-Reyes, 2014; Umans et al., 2018).

Garcia e Tavares (2017) apresentam uma evolução histórica dos princípios da governança. Em empresas familiares, a Governança Familiar segue princípios semelhantes, buscando facilitar o relacionamento de seus membros por meio de estruturas e instrumentos, separando sua atuação nas três diferentes dimensões (Parada et al., 2016; Steinberg e Blumenthal, 2011). 
Várias estruturas de governança podem ser formadas nas empresas. Steinberg e Blumenthal (2011) apresentam um modelo interessante - que será utilizado neste artigo (Figura 4) -, explicitando o relacionamento entre os mecanismos. Esse modelo é similar a outros apresentados na literatura, como Gersick et al. (2017) e Suess-Reyes (2014).

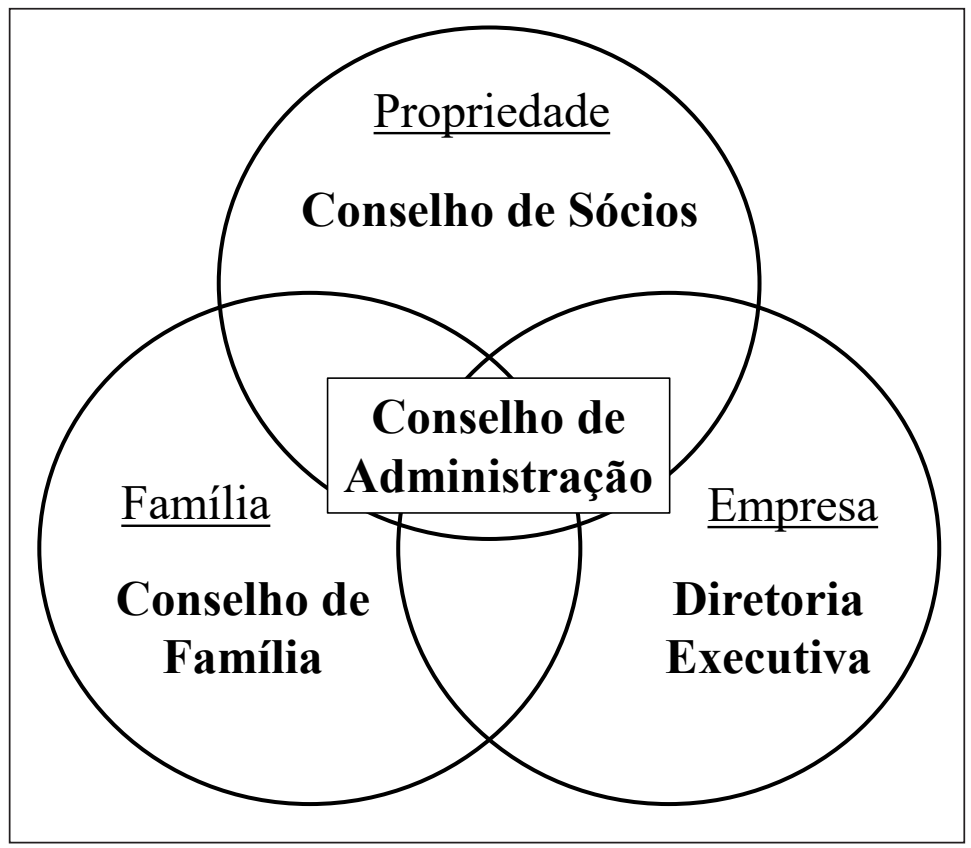

Figura 4. Mecanismos de Governança Familiar

Fonte: Adaptado de Steinberg e Blumenthal (2011)

\section{Governança na dimensão empresa}

$\mathrm{Na}$ dimensão empresa, a diretoria executiva cumpre a visão do Conselho de Administração, enquanto é fiscalizada, e presta contas a ele (Steinberg e Blumenthal, 2011). Em uma empresa familiar, o relacionamento nessa dimensão pouco se diferencia de uma empresa não-familiar. Contudo, em uma empresa familiar, a diretoria executiva pode ser composta apenas por gestores da família, apenas por gestores não-familiares (também chamados de profissionais) ou de uma combinação de ambos (Gersick et al., 2017). Se a decisão for pelo envolvimento de membros da família, é essencial a implementação de um plano para desenvolvimento das habilidades de gestão dos membros da família, bem como regras para seleção dos membros mais adequados para cada cargo e função.

$\mathrm{Na}$ empresa foco, a diretoria executiva sempre foi ocupada apenas por membros da família. Na Fase 1, pelo fundador, uma vez que, embora sua esposa o auxiliasse, ela não geria a empresa. Na Fase 2, o filho mais velho se juntou ao fundador. Por fim, na Fase 3, foi a vez de um genro e dois netos do fundador assumirem a diretoria executiva, dado que já trabalhavam na organização e tinham conhecimentos práticos sobre como ela funcionava. Isso foi uma vantagem fundamental para a sobrevivência da empresa à transição não planejada.

Contudo, passado o período inicial da transição, os sócios da empresa começaram a discutir a entrada de diretores não membros da família com o objetivo de "tornar a empresa mais profissional" e "compatível com a realidade de mercado", como relatado nas entrevistas. No entanto, ao questionar esses comentários, os pesquisadores identificaram que o objetivo de se introduzir diretores não familiares era facilitar a cobrança de resultados. Os diretores familiares apresentavam resistência à cobrança dos sócios e à prestação de contas, uma vez que, anteriormente, a organização era gerida de maneira centralizada, com rápidas decisões, desejando-se manter esse cenário. Essa dificuldade é parcialmente explorada na literatura por Maglio et al. (2014), Umans et al. (2018) e Zona (2016), os quais abordam a influência das emoções no relacionamento entre o Conselho de Administração e os diretores, sendo essa relação dificultada pela existência de laços familiares entre os membros. Exceção feita a esse ponto, a diretoria 
executiva foi o mecanismo que sofreu menor alteração ao longo da transição, dado que já existiam dois diretores executivos, ambos familiares.

Ainda sobre a dimensão empresa, ao longo da transição foram estabelecidas regras para a entrada de membros da família na organização, dado o grande número de netos do fundador (nove) e perspectiva de número superior de bisnetos (no momento da pesquisa haviam seis bisnetos). Assim, familiares poderiam realizar estágio na empresa, desde que adequado ao curso superior em que estavam matriculados. Já para uma vaga de emprego, era necessária aprovação de maioria simples do conselho administrativo da empresa, após uma triagem inicial comprovando a qualificação e experiência para o cargo almejado.

\section{Governança na dimensão propriedade}

Na dimensão propriedade, o Conselho de Sócios (chamado de Reunião de Acionistas por Gersick et al., 2017), do qual participam todos os acionistas da empresa, possui caráter informativo sobre a atuação da empresa e os resultados financeiros do último período. Em geral, ocorre uma vez ao ano e é quando são eleitos os membros do Conselho de Administração.

Na empresa foco, com a ajuda de uma consultoria externa, a família decidiu constituir o Conselho de Administração com quatro cadeiras, cada uma delas referente a um dos núcleos familiares (filhos) do fundador. A fundadora, por sua vez, devido a problemas de saúde, não participava do Conselho de Administração. Ocupando a cadeira do filho mais velho do fundador, optou-se por um de seus dois filhos (neto do fundador), que assumiu a cadeira no Conselho de Administração, após alinhamento interno com seu irmão.

Dado que a maioria de sócios já participava do Conselho de Administração, o papel do Conselho de Sócios foi reduzido e a família decidiu que voltaria a estudar a implementação desse mecanismo quando mais netos tivessem direito a propriedade, ou seja, após o falecimento de mais filhos do fundador, pois, nesse momento, existiria um número maior de sócios sem participação no Conselho de Administração. Gnan et al. (2013) apresentam recomendação similar na literatura, ao afirmarem que em pequenas e médias empresas familiares é usual que o Conselho de Administração seja a única estrutura de governança em conjunto com a diretoria executiva.

Apesar de o Conselho de Sócios não ter sido implementado, verificou-se no contrato social da empresa regras claras para a divisão de propriedade. No caso de falecimento de um sócio, a propriedade era dividida entre seus filhos (seus cônjuges, por sua vez, não tinham direito a participação da empresa). Já no caso de um sócio decidir vender a sua participação, ela primeiramente deveria ser oferecida ao seu núcleo familiar, depois aos outros núcleos familiares e, em última instância, a terceiros. Desse modo, objetiva-se que o controle acionário da empresa continue exclusivamente com familiares.

\section{Governança na dimensão família}

Na dimensão da família, uma estrutura importante é o Conselho de Família, que busca aproximar os familiares, especialmente no estágio do Consórcio entre Primos, quando há uma tendência ao distanciamento entre as pessoas (Steinberg e Blumenthal, 2011). Para Gnan et al. (2013) essa é a principal estrutura de governança familiar, pois ela molda o relacionamento entre os membros da família.

Os agregados (cônjuges) podem ser incluídos no conselho ou não, conforme conveniência dos familiares (Gersick et al., 2017). Dependendo da empresa, pode-se oficializar as regras dessa estrutura por meio de um estatuto. Além disso, é recomendado que o chefe da empresa não seja o chefe do conselho de família, facilitando a separação entre as dimensões e possibilitando que haja ao menos um representante de cada núcleo familiar no conselho (Steinberg e Blumenthal, 2011).

Na organização foco, a separação dos chefes da empresa e da família foi obtida, já que as sócias (filhas do fundador) assumiram a chefia da família, enquanto um genro e dois netos do fundador, a diretoria executiva (chefia da empresa). Contudo, não existem regras formais para funcionamento desse conselho, de modo que, muitas vezes, encontros em datas comemorativas são utilizados para que os familiares que não fazem parte da empresa ou do Conselho de Administração tenham informações sobre 
o desenvolvimento da organização, resultados financeiros e outras informações relacionadas à empresa.

Ao longo das entrevistas, verificou-se, tanto do ponto de vista dos sócios quanto dos familiares que não eram proprietários, que essa estrutura não funcionava corretamente, porém, isso não lhes trazia impacto. Questionando sobre essa afirmação, verificou-se que isso era decorrente do fato de os familiares terem fácil acesso a membros do Conselho de Administração (mães, irmão e avós), bem como do fato de as reuniões em datas comemorativas terem caráter pouco informativo, prevalecendo o encontro social.

Apesar dessa constatação, segundo Gersick et al. (2017), Steinberg e Blumenthal (2011) e SuessReyes (2014), os principais objetivos do Conselho de Família são:

- Discutir o envolvimento da família na empresa, bem como seus valores e políticas a longo prazo;

- Passar para as gerações mais novas as origens da família e da empresa, assim como suas histórias;

- Esclarecer os limites entre a empresa e a família, criando um fórum para que os membros da família que não são proprietários ou não trabalham na empresa também possam ser ouvidos;

- Formar as gerações, especialmente as mais novas, nos assuntos relacionadas a empresas familiares;

- Discutir a regra de entrada de familiares na empresa, o planejamento da sucessão e a estrutura de divisão de propriedade para a próxima geração;

- Formalizar o canal de comunicação, separando os encontros familiares informais, como aniversários e natal, de reuniões formais.

Entre esses seis objetivos, os quatro primeiros tornam-se menos relevantes enquanto cada membro da família for próximo de ao menos um membro do Conselho de Administração. Além disso, a proximidade com o fundador (todos os membros do conselho conviveram com o fundador por pelo menos 30 anos), facilita a transmissão da origem e valores da empresa para as gerações mais novas. 0 quinto objetivo também é menos relevante, dado que durante a sucessão as regras foram formalmente estabelecidas em acordo entre os sócios e os membros da família.

O sexto objetivo, porém, é um aspecto importante a ser considerado, pois atualmente não há separação clara entre o encontro social e as informações sobre a empresa, como afirmam Umans et al. (2018). Desse modo, recomenda-se a criação de uma ou duas datas específicas ao ano (não festivas) para discussão sobre a empresa.

Assim, analogamente ao Conselho de Sócios, o Conselho Familiar também possui perspectiva de tornar-se mais importante à medida que o número de membros da família aumente e que estes se distanciem. Contudo, sua importância, logo após o processo sucessório na empresa foco, é baixa.

\section{Conselho de Administração}

O Conselho de Administração (denominado Conselho de Sócios por Gersick et al., 2017) separa as dimensões da propriedade, da família e da empresa através da governança (Garcia e Tavares, 2017). 0 conselho possui como papéis fundamentais: i) representar os interesses dos proprietários; ii) formular e monitorar o objetivo estratégico a longo prazo da empresa e; iii) aconselhar a diretoria executiva na tomada de decisões (Steinberg e Blumenthal, 2011; Umans et al., 2018). Ao acompanhar uma reunião do conselho na empresa foco, verificou-se que esses três papéis fundamentais eram plenamente cumpridos, embora existisse dificuldade dos sócios em cobrar resultados dos diretores familiares.

Assim como na diretoria executiva, o Conselho de Administração também pode ser formado exclusivamente por membros da família, membros não-familiares ou uma combinação dos dois, dependendo da cultura local, das tradições da família e do estágio evolutivo da empresa (Brenes el al., 2011). Gersick et al. (2017) recomenda que ao menos dois conselheiros sejam familiares, de modo que eles façam a ligação dessa estrutura com o Conselho Familiar. No caso da empresa foco, o conselho é formado apenas por familiares, especificamente por quatro sócios (um de cada núcleo familiar), os conselheiros. 
Outro ponto importante destacado na literatura é que não se recomenda que gerentes da empresa se tornem conselheiros, bem como que antigos funcionários sejam contratados como conselheiros em função de vínculo e/ou amizade (Gersick et al., 2017). Isso não ocorre na empresa foco, mas, ao contrário do sugerido na literatura, ocorre a participação de familiares não-sócios no Conselho de Administração,, dado que cada conselheiro pode levar à reunião um convidado, ainda que sem poder de voto (Gersick et al., 2017).

O Conselho de Administração foi o primeiro mecanismo a ser constituído após o processo de sucessão e suas reuniões iniciais foram pautadas pela definição de regras de convívio e pela construção do acordo societário, bem como pelo interesse conjunto dos sócios na continuidade da empresa e em seus papéis como sócios da organização. Nas reuniões iniciais, definiu-se o modelo de quatro conselheiros representando cada um dos núcleos familiares, assim como a seleção do chefe do conselho, entre os quatro conselheiros, pelo período de um ano. Ao final desse período, outro conselheiro assumiria a chefia do mecanismo.

Definiu-se, também, a realização de reuniões mensais, às $14 \mathrm{~h} 30 \mathrm{~min}$ da terceira sexta-feira de cada mês, com necessidade de participação dos quatro conselheiros e ao menos um dos diretores executivos, embora a participação dos três fosse recomendada, de modo a constituir integração entre a estratégia da empresa e sua execução. Essas regras tornaram o mecanismo muito importante, na visão dos sócios, familiares e funcionários, uma vez que todos entenderam se tratar do fórum no qual seriam tomadas as principais decisões relativas à empresa e à propriedade.

Entre os entrevistados, três faziam parte do Conselho de Administração e, de acordo com sua avaliação, o conselho não apenas facilitava a tomada de decisão, mas suas reuniões eram importantes por criarem cadência para que eles acompanhassem o desenvolvimento da empresa. Além disso, especialmente para as filhas do fundador (todas conselheiras), a participação no conselho trouxe-lhes abertura para expressar suas opiniões e desejos quanto à empresa, algo que não lhes era permitido na Fase 2, quando o irmão mais velho e o fundador tomavam todas as decisões sozinhos.

\section{Importância dos mecanismos de Governança Familiar}

Apresentados os quatro principais mecanismos de governança familiar, a Tabela 1 resume a importância de cada um desses mecanismos na empresa foco. Nota-se que, a diretoria executiva era o único mecanismo implementado antes do processo de sucessão, sendo vista, ainda, como importante tanto pelos sócios quanto pelos funcionários e pelos familiares, pois é nessa esfera que as principais decisões diárias são tomadas, influenciando significativamente os resultados apresentados pela empresa.

Tabela 1. Importância dos mecanismos de Governança Familiar na empresa foco

\begin{tabular}{lcccc} 
Mecanismo de Governança & Diretoria Executiva & Conselho de Sócios & Conselho de Família & $\begin{array}{l}\text { Conselho de } \\
\text { Administração }\end{array}$ \\
Familiar & Empresa & Propriedade & Família & Todas \\
\hline Dimensão & Sim & Não & Não & Não \\
Existência antes da sucessão & Sim & Não & Sim & Sim \\
\hline Implementado & Sim & Não & Média & Sim \\
\hline Funciona segundo teoria & Alta & Baixa & Baixa & Alta \\
\hline Importância para os sócios & Alta & Baixa & Média & Alta \\
\hline Importância para os funcionários & Alta & & & Baixa
\end{tabular}

Fonte: Resultados originais da pesquisa

O Conselho de Administração, por sua vez, foi implementado após a sucessão, mas a formalização de regras para seu funcionamento, bem como a obrigatoriedade de participação dos quatro conselheiros e de ao menos um administrador, trouxeram grande importância ao mecanismo. Além disso, sócios, familiares e funcionários entendem que é nessa esfera que são tomadas as decisões estratégicas e a longo prazo, que podem afetar diretamente todos os membros da família, da empresa e da propriedade.

Já o Conselho de Sócios apresenta baixa importância para os sócios, uma vez que a maioria participa também do Conselho de Administração. Para os familiares, a importância também é baixa, dado que a 
maioria não tem direito à propriedade no momento e não poderia participar do Conselho de Sócios se ele existisse. Por fim, os funcionários demostraram não entender a diferença entre o Conselho de Sócios e o Conselho de Administração, entendendo que o primeiro mecanismo não era necessário.

Para o Conselho Familiar, verificou-se discrepância na importância dada entre as dimensões e entre pessoas de uma mesma dimensão. Para os funcionários, a importância é baixa, pois eles entendem que a proximidade com familiares-funcionários é suficiente para garantir que a família entenda a importância da empresa. Nesse contexto, seria papel dos familiares que trabalham na empresa comunicar aqueles que não trabalham sobre o desenvolvimento e resultados obtidos pela organização.

Para os sócios, em geral, pais e mães dos demais familiares, seria importante haver um encontro para aproximar os membros da família e transmitir a história da empresa. Notou-se nesses um interesse de que seus filhos também trabalhassem na empresa. Outro grupo atribuiu baixa importância ao mecanismo, demonstrando interesse em ver os filhos seguindo outras carreiras vinculadas as suas preferências pessoais, em vez de vê-los trabalhando na empresa.

Para os familiares, notou-se uma divisão similar ao identificado entre os sócios. Contudo, a divisão foi fruto do interesse dos descentes em trabalhar na organização e não do desejo de seus pais. Identificou-se, também, que aqueles com maior interesse na organização buscavam informações sobre o seu funcionamento, não apenas com os conselheiros, mas também com os membros da família que participavam da empresa.

\section{Conclusão}

Por meio do estudo de caso, verificou-se que a Diretoria Executiva e o Conselho de Administração são os mecanismos de governança familiar mais importantes para a continuidade da empresa após um processo de sucessão, especialmente na transição do estágio do Proprietário Controlador para a Sociedade entre Irmãos. O Conselho de Sócios torna-se relevante quando muitos dos sócios não participam do Conselho de Administração. Já o Conselho de Família mostrou-se relevante para membros que desejam atuar futuramente como funcionários da empresa, mas pouco importantes para os demais, desde que os familiares tenham fácil acesso a um conselheiro para se manterem informados sobre os resultados e desenvolvimento da empresa. Desse modo, recomenda-se priorizar a implementação da Diretoria Executiva e o Conselho de Administração frente aos demais mecanismos de governança familiar.

Contibuição dos autores: Concepção: Bagni, G.; Pinheiro, C.R. Coleta de dados: Bagni, G.; Pinheiro, C.R. Análise dos dados: Bagni, G.; Pinheiro, C.R. Definição da metodologia: Bagni, G.; Pinheiro, C.R. Redação e edição: Bagni, G.; Pinheiro, C.R.

Como citar: Bagni, G.; Pinheiro, C.R. 2021. Implementação de governança familiar em uma empresa de transportes do interior de São Paulo. Quaestum 2: e26750591

\section{Referências}

Brenes, E.R.; Madrigal, K.; Requena, B. 2011. Corporate governance and family business performance. Journal of Business Research, 64(3): 280-285.

Brown, F.H. 2006. Reweaving the family tapestry: a multigerational approach to families. Norton, New York, NY, USA.

Dawson, A.; Mussolino, D. 2014. Exploring what makes family firms different: discrete or overlapping constructs in the literature? Journal of Family Business Strategy, 5(2): 169-183.

Donnelley, R.G. 1964. The family business. Harvard Business Review, 42(4): 93-105.

Dyer Jr., W.G.; Dyer, W.J. 2009. Putting the family into family business research. Family Business Review, 22(3): 216-219.

Gallo, M.A.; Sveen, J. 1991. Internationalizing the family business: facilitating and restraining factors. Family Business Review, 4(2): 181-190.

Garcia, R.L.; Tavares, C.K. 2017. Empresa familiar e a governança coorporativa: breves apontamentos sobre as estruturas de gestão das empresas familiares. Revista de Estudos e Pesquisas Avançadas do Terceiro Setor, 4(1): 481-516.

Gedajlovic, E.; Carney, M.; Chrisman, J.J; Kellermanns, F.W. 2012. The adolescence of family firm research: taking stock and planning for the future. Journal of Management, 38(4): 1010-1037.

Gersick, K.E.; Davis, J.A.; Hampton, M.M.; Lansberg, I. 2017. De geração para geração: ciclos de vida das empresas familiares. Alta Books, Rio de Janeiro, RJ, Brasil.

Gnan, L.; Montemerlo, D.; Huse, M. 2013. Governance systems in family SMEs: the substitution effects between family councils and corporate governance mechanisms. Journal of Small Business Management, 53(2): 355-381. 
Harms, H. 2014. Review of family business definitions: cluster approach and implications of heterogeneous application for family business research. International Journal of Financial Studies, 2: 280-314.

Howell, M.T. 2009. Critical success factors simplified. Productivity Press, New York, NY, USA.

Instituto Brasileiro de Governança Coorporativa (IBGC). 2008. Governança coorporativa em empresas de controle familiar. Saint Paul Editora, São Paulo, SP, Brasil.

Lefebvre, M.R.; Lefebvre, V. 2016. Anticipating intergenerational management transfer of family firms: a typology of next generation's future leadership. Futures, 75: 66-82.

Litz, R.A. 1995. The family business: toward definitional clarity. Family Business Review, 8(2): 71-81.

Lodi, J.B. 1998. A empresa familiar. 5ed. Pioneira, São Paulo, SP, Brasil.

Longenecker, J.G.; Moore, C.W.; Petty, J.W. 1997. Administração de pequenas empresas. Makron Books, São Paulo, SP, Brasil.

Maglio, S.J.; Gollwitzer, P.M.; Oettingen, G. 2014. Emotion and control in the planning of goals. Motivation and Emotion, 38: 620-634.

Massis, A.; Kotlar, J.; Frattini, F.; Chrisman, J.J.; Nordqvist, M. 2016. Family governance at work: organizing for new product development in family SMEs. Family Business Review, 29(2): 1-25.

Mathews, T.; Blumentritt, T. 2015. A sequential choice model of family business succession. Small Business Economics, (45): 15-37.

Muttakin, M.B.; Monem, R.M.; Khan, A.; Subramaniam, N. 2015. Family firms, firm performance and political connections: evidence from Bangladesh. Journal of Contemporary Accounting \& Economics, 11(3): 215-230.

Nascimento, J.O.; Martins, F.R.C.; Zittei, M.V.M.; Lugoboni, L.F.; Araújo, J.A.O. 2016. Estrutura formal e instrumentos da controladoria em empresas familiares que buscam implementam boas práticas de governança coorporativa. Revista Metropolitana de Governança Coorporativa, 1(2): 3-25.

Nekhili, M.; Nagati, H.; Chtioui, T.; Rebolledo, C. 2017. Corporate social responsibility disclosure and market value: family versus nonfamily firms. Journal of Business Research, 77: 41-52.

Oliveira, J.R.; Albuquerque, A.L.; Pereira, R.D. 2012. Governança, sucessão e profissionalização em uma empresa familiar: (re)arranjando o lugar da família multigeracional. Revista Brasileira de Gestão de Negócios, 14(43): 176-192.

Parada, M.J.; Müller, C.; Gimeno, A. 2016. Family firms in ibero-america: an introduction. Academia Revista Lationoamericana de Administración, 29(3): 219-230.

Pimenta, E.G.; Abreu, M.L.L. 2014. Conceituação jurídica da empresa familiar. p. 49-64. In: Coelho, F.U.; Féres, M.A. Empresa familiar: estudos jurídicos. Saraiva, São Paulo, SP, Brasil.

Prado, R.N. 2011. Empresas familiares: governança corporativa, governança familiar e governança jurídica. p. 1970. In: Prado, R.N. Empresas familiares: governança corporativa, governança familiar e governança jurídica. Saraiva, São Paulo, SP, Brasil.

Ramadani, V.; Hoy, F. 2015. Context and uniqueness of family businesses. p. 9-37. In: Dana, L.P.; Ramadani, V. Family business in transition economies. Springer Link, New York, NY, USA.

Rockart, J.F. 1979. Chief executives define their own data needs. Harvard Business Review, 52(2): 81-93.

Steiger, T.; Duller, C.; Hiebl, M.R.W. 2015. No consensus in sight: an analysis of ten years of family business definitions in empirical research studies. Journal of Enterprising Culture, 23(1): 25-62.

Stein, J. 1988. Takeover threats and managerial myopia. Journal of Political Economy, 96: 61-80.

Steinberg, H.; Blumenthal, J. 2011. A família empresária: organizando as relações de afeto, poder e dinheiro por meio da governança corporativa. Editora Gente, São Paulo, SP, Brasil.

Suáre, K.C.; Santana-Martín, D.J. 2004. Governance in Spanish family business. International Journal of Entrepreneurial Behaviour \& Research, 10(1-2): 141-163.

Suess-Reyes, J. 2014. Family governance: literature review and development of a conceptual model. Journal of Family Business Strategy, 5(2): 138-155.

Tagiuri, R.; Davis, J.A. 1996. Bivalent attributes of the family firm. Family Business Review, 2(9): 199-208.

Tharawat Magazine. 2014. Economic impact of family businesses: a compilation of facts. Disponível em: <www. tharawat-magazine.com/economic-impact-family-businesses/economic-impact-family-businesses-2-2/\#gs. fRnRxLA>. Acesso em: set. 15, 2018.

Tondo, C. 2008. Empresas familiares e famílias empresárias: uma introdução.p. 21-39. In: Tondo, C. Desenvolvendo a empresa familiar e a família empresária. Sulina, Porto Alegre, RS, Brasil.

Umans, I.; Lybaert, N.; Steijvers, T.; Voordeckers, W. 2018. Succession planning in family firms: family governance practices, board of directors, and emotions. Small Business Economics, 54: 189-207.

Voss, C.; Tsikriktsis, N.; Frohlich, M. 2002. Case research in operations management. International Journal of Operations and Production Management, 22(2): 195-219.

Werner, R.A.I. 2011. Teoria e prática da governança familiar: aspectos tangíveis e intangíveis. p. 175-199. In: Prado, R.N. Empresas familiares: governança corporativa, familiar e jurídico-sucessória. Saraiva, São Paulo, SP, Brasil.

Yu, A.; Lumpkin, G.T.; Sorenson, R.L.; Brigham, K.H. 2012. The landscape of family business outcomes: a summary and numerical taxonomy of dependent variables. Family Business Review, 25(1): 33-57.

Zellweger, T.M.; Nason, R.S.; Nordqvist, M. 2012. From longevity of firms to transgenerational entrepreneurship of families: introducing family entrepreneurial orientation. Family Bussiness Review, 25: 136-155.

Zona, F. 2016. CEO leadership and board decision processes in family-controlled firms: comparing family and non-family CEOs. Small Business Economics, 47: 735-753. 